\title{
Environmental education for youth and adults: a bibliometric analysis of research
}

\author{
Kateryna Onopriienko ${ }^{1}$, Volodymyr Onopriienko ${ }^{2}$, Yurii Petrushenko ${ }^{3}$, and Iryna Onopriienko ${ }^{4}$ \\ ${ }^{1} \mathrm{PhD}$ student, Department International Economic Relations, Sumy State University, Ukraine \\ ${ }^{2}$ Doctor of Pedagogy, Department of Ecology and Botany, Sumy National Agrarian University, Ukraine \\ ${ }^{3}$ Doctor of Economics, Department International Economic Relations, Sumy State University, Ukraine \\ ${ }^{4} \mathrm{PhD}$ in Economics, Department of Marketing and Logistics, Sumy National Agrarian University, Ukraine
}

\begin{abstract}
In recent years there has been a sharp increase in the interest of humanity to environment preservation. It has become clear that the reckless use of nature will sooner or later lead to a catastrophe that will have not only environmental, but also economic and social consequences. The article provides a bibliographic analysis of scientific papers from around the world on the basis of Scopus with the keywords "environmental education" and "environmental adult education" for the period 1968 - 2019. It was found that in this regard most attention is paid to the US authors. The scientific works of the authors, who are the leaders in terms of the number of publications on environmental education of adults, have been studied. With the help of Vosviewer software it was determined which countries publish the biggest and the smallest number of scientific papers with the keyword "environmental adult education". Scientific works of domestic scientists were also analyzed. Adult education is becoming important in addition to the classic concept of school education. The article analyzes, which fields of science have the biggest and the smallest number of scientific papers with the keyword "environmental adult education", where social and environmental sciences became the leaders.
\end{abstract}

\section{Introduction}

The expediency of environmental education of adults is a well-known fact, because the vast majority of countries in one sense or another owe their technological, sociocultural and economic progress to this field of education.

In the same way, they represent a vector of their further socio-economic growth through its development. However, modern realities require a significant acceleration and renewal of the complex of conditions, the implementation of which directly depends on environmental education of the adult population.

Human development begins with education, however, it does not end with school education, but should last a lifetime. Therefore, the environmental education of youth and adults is gaining new relevance. The excessive consumption and production of various synthetic substances creates imbalances in nature while human beings are direct participants in this process. Adults apply modern technologies, the power of which can be used by incompetent and indifferent people with possible unpredictable consequences. Adults educate the new generation by passing on knowledge, experience and values from adults to the younger generation. At the same time, as we know, the educational impact begins with copying the actions of adults. These positions justify the need to raise the level of ecological culture of society as a whole, focusing adult education on the formation of moral values, awareness of their personal role in creating a harmonious relationship between society and environment.

\section{Analysis of research}

The whole history of human development and the evolution of education lead to the conclusion that learning is the main type of human activity, it is a lifestyle. This became especially clear in the late twentieth and early twenty-first century, when humanity finally realized that the main danger to its existence lies not so much in global crises, not in the imperfections of man himself, but in the growing gap between the inner world and competences of man and changes in the outside world.

Adult education is considered from many angles. Yu. Petrushenko et al pay attention to ensuring the quality of education and equal access to it through life. It combines several important vectors of adult education: quality, equity, accessibility, engagement and comprehensive encouragement. Among the factors the author singles out such concept as "Learning to Live Together". For its analysis he studies such indicators as "participation in the work of voluntary or charitable organizations, including the environmental ones, the implementation of measures to preserve the natural environment"[1]. 
The definition of environmental education is usually associated with the first conference on this topic, held in 1970 in Carson City (USA, Nevada). The following wording was adopted there: "Environmental education is a process of a person's awareness of the value of the environment and clarification of the basic provisions necessary to obtain the knowledge and skills necessary to understand and recognize the interdependence between a person, his culture and his biophysical environment. Environmental education also includes the development of practical skills in solving problems related to interaction with the environment, the development of behavior that contributes to the improvement of the quality of the environment. [2]

At a certain stage it is necessary to study the number of bibliographic sources to assess the state of development of environmental education of adults.

Using the "title, abstract, keywords" field of search in the Scopus database, different outcomes in terms of the number of papers (conference papers, books, chapters and articles in the journals) were identified for search items. The combination of the terms allowed us to gain an understanding of the evolution of the field of study (please see Figure 1), to reveal current and predict emerging of the new fields of research.

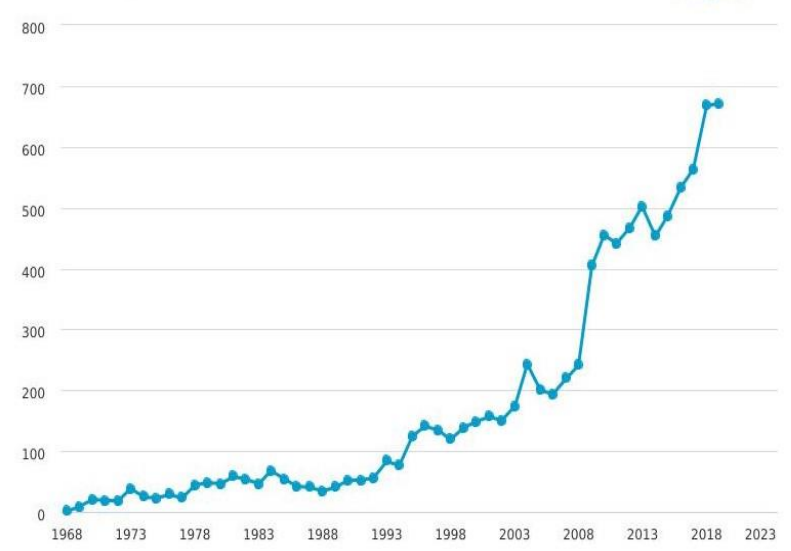

Fig. 1. Publishing trends (number of papers) in the area of "environmental education" (using Scopus Database).

The trend of using the term "environmental education" has been growing since 2003. It was in the early 2000s that the topic of environment became the world issues, which were actively discussed. The concepts of land pollution and global warming were studied in schools and universities, beginning to be introduced in the field of adult education. The first scientific works were written in the 1960s.

The bibliographic analysis of the topic revealed the total number of articles written with the keyword "environmental education" in the Scopus database. As of 2019, the number of scientific papers was already 9319 , while only 24 articles with the keyword "environmental adult education" were found. Therefore, it should be noted that the issue of environmental adult education is insufficiently disclosed at the global level, which determines the relevance of the chosen topic.

The first article with the keyword "environmental education" was written in 1968 (according to the Scopus database). In particular, it was noted that techniques in the conservation and management of natural resources which have been developed through research and practical experience are not being adopted on a widespread scale, partly because of inadequacies in education about the environment. The functions of environmental education are being discussed, the characteristics of environmental education are being outlined. The need for educational research is stressed, particularly on the relationships between educational objectives and the requirements of society in terms of preparing young people to have a greater sense of awareness of their environment, and of the need for appropriately trained specialists. The author of the article is T. Pritchard - a native of Wales, who later migrated to the USA. Therefore, the issue of environmental education in the 1960s was raised in America. [1]

We can also say that in April 2020 the largest number of studies with the keyword "environmental education" was done in the United States, followed by England and Australia. Ukraine is not a leader in this rating, which opens new opportunities for the further study the topic. The data were analyzed by using Vosviewer software (see Figure 2).

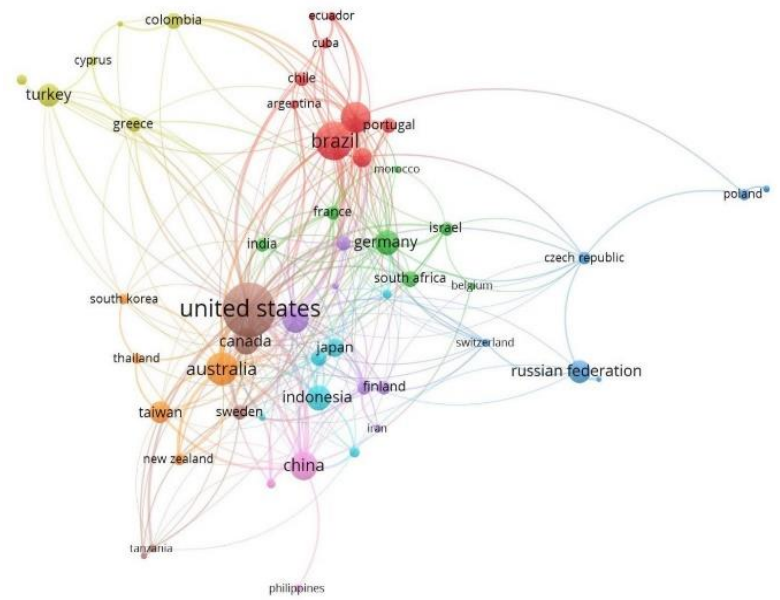

Fig. 2. Networks map between the keywords of articles published on environmental education.

Examining the phenomenon of America we found that environmental education in the United States has two levels: ecological and environmental. They are closely related and complementary. The ecological level covers the issues of natural dynamic balances, organization of the biosphere, heredity, adaptation and changes in nature. At the environmental level special attention is paid to the issues of rational nature management, nature protection and human impact on the environment. Skills and abilities are an integral part of education. They are divided into individual and exploratory. The former contribute to the effective understanding of environmental knowledge, the latter are aimed at mastering the methods of independent creative research by pupils and students. Every school, university and adult educational institution has an environmental discipline. Students have the right to choose it or not, but 
in $90 \%$ of cases young people participate in various types of environmental projects [3].

\subsection{Bibliometric analysis by authors}

After analyzing the number of articles with the keyword "environmental education" we identified the top 10 authors who publish their research on this topic. These included Fien J., Gough A, Kopnina H. and others. (see Figure 3)

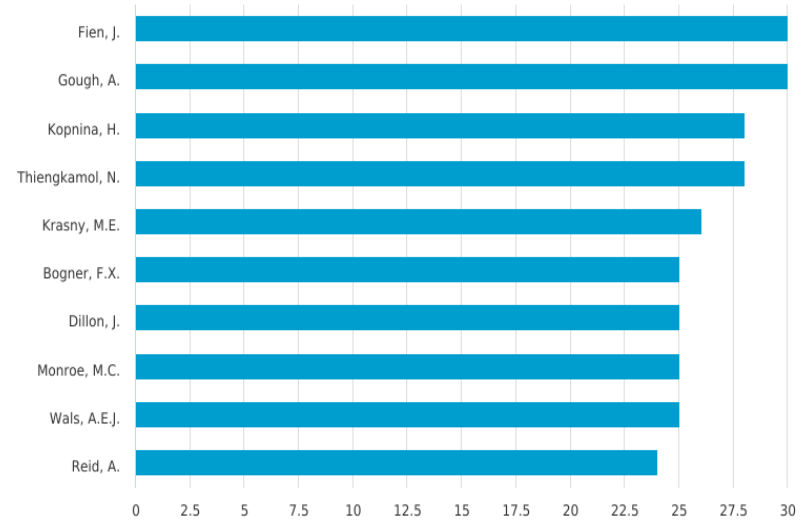

Fig. 3. The top 10 contributing authors in the area of environmental education (Scopus Database), full counting.

In his research, Fien $J$. notes that many environmental problems are desperately in need of attention. Educating both adults and young people is seen as part of the solution to such problems. Given this situation, and the already considerable investment in environmental education in schools, the notion of encouraging students to initiate environmental discussions with adults at home and in the community seems attractive and worthy of investigation. Education and social science are viewed as literature concerning intergenerational influence. An approach is outlined to guide future efforts in research and program development aimed at encouraging students to act as catalysts of environmental communication and learning beyond school boundaries. [3]

In his works, Gough A. studies environmental education and education for sustainable development (ESD). The author notes that changing ways of "environment" represent in the discourses of environmental education and education for sustainable development in the United Nations. It draws on the writings of Jean-Luc Nancy and discusses the increasingly dominant view of the environment as a natural resource base for economic and social development and how this instrumentalisation of nature is produced by discourses and ecotechnologies that identify and define the natural realm in our relationship with it. This denaturation of nature is reflected in the priorities for sustainable development discussed at Rio+20 and proposed successor UNESCO projects. They argue for the need to reassert the intrinsic value of 'environment' in education discourses and discusses strategies for so doing. It is intended as a wake-up call to the changing context of the 'environment' in ESD discourses. In particular, we need to respond to the recent UNESCO direction of global citizenship education that continues to reinforce an instrumentalist view of the environment as part of contributing to 'a more just, peaceful, tolerant, inclusive, secure and sustainable world". [4]

In turn, Kopnina H. notes the following view on the issue: "Building on the Millennium Development Goals, Education for Sustainable Development (ESD) and Education for Sustainable Development Goals (ESDG). Despite the willingness of many educational institutions worldwide to embrace the SDGs, given escalating sustainability challenges we question whether ESDG is desirable as "an education for the future". Many challenges outlined by the SDGs are supposed to be solved by "inclusive" or "sustainable" economic growth, assuming that economic growth can be conveniently decoupled from resource consumption. Yet, the current hegemony of the sustainability-through-growth paradigm has actually increased inequalities and pressure on natural resources, exacerbating biodiversity loss, climate change and resulting social tensions. With unreflective support for growth, far from challenging the status quo, the SDGs and consequently, the ESDGs, condone continuing environmental exploitation, depriving millions of species of their right to flourish, and impoverishing future generations. We create greater awareness of the paradoxes of sustainable development and encourage teaching for sustainability through various examples of alternative education that emphasizes planetary ethic and degrowth. The alternatives include Indigenous learning, ecopedagogy, ecocentric education, education for steady-state and circular economy, empowerment and liberation". [5]

$\mathrm{N}$. Thiengkamol conducts his research in the field of environmental adult education and defines the concept of Environmental Education Characteristics. In his works the author notes that Environmental Education Characteristics (EECs) are features for environmental educator or environmental education volunteer should have public mind to serve community and society in terms of awareness and consciousness raising, attitude, belief and behavior changing through knowledge giving activities. The lack of evidence for confirmation of EECs, it needs to employ the experts in environmental education field to validate. Environmental education expert refers to the person who graduated at doctoral degree in the environmental education field or related field and has experience at least 5 years in research or teaching or holding training environmental education program in this field. Environmental education principles cover knowledge and understanding on environmental issues, awareness raising, attitude and behavioral changing including valuating ability, skill development and participation. [6]

The works of M. Krasny are focused on urban environmental education. The researcher emphasizes that urban environmental education encompasses place-based and action-oriented stewardship practices, including community gardening and vegetable production, often with the dual goals of developing youth and community 
assets. Yet in-depth understanding of how these goals are achieved is lacking. Using narrative inquiry, we explored participant experiences in a multi-year agriculture internship program conducted by the food justice organization East New York Farms! (ENYF) in Brooklyn, NY. Emerging from our conversations with youth were five themes defining their intern experience: ENYF as somewhere to belong, to be pushed, to grapple with complexity, to practice leadership, and to become yourself. We propose a theory of change that emphasizes politicized notions of caring as a foundation for cultivating developmental assets, including competence, contribution, and critical consciousness, among youth who participate in ENYF programs multiple years. [7]

The study found that the articles (only 24 items) with the keyword "environmental adult education" were also dominated by authors from the United States.

In particular, Fitzwilliams-Heck C. J. notes: "The study conceptualizes environmental adult education as an engaging, inclusive, and active educational approach influenced and shaped by multiple disciplines and theories, that informs and empowers adult learners. While educators can transform learning experiences into the understanding and action of adults to address the root causes and possible responses that will eliminate triggers of environmental problems, few actual environmental adult education experiences have been examined to date". [8]

Considering art as a tool of environmental adult education Walter P. mentions: "The potential of the arts is an instrument of environmental adult education, of creative subversion, of public intervention and of engagement that confronts, includes, mobilizes, educates, and challenges for a better world. That is, it opens up democratic, political space for dialogue when this is denied to citizens". [9]

According to Alsaadat K., environmental education is a process in which individuals gain awareness of their environment and acquire knowledge, skills, values, experiences, and also the determination, which will enable them to act - individually and collectively - to solve present and future environmental problems. EE is a complex process, covering not just events, but a strong underlying approach to society building as a whole. EE provides people with the awareness needed to build partnerships, understand NGO activities, develop participatory approaches to urban planning, and ensure future markets for eco-business.in conjunction with this issue comes environmental adult education which brings an ecological perspective to studies of adult learning by concretizing the interconnections between people's experiences of environmental deterioration and recognition of the destructive powers of the global economy. [10]

Therefore, we see that the research of scientists has different vectors, which in one way or another intersect in the concept of "environmental adult education".

Many domestic scientists deal with the issue of "environmental education": Onopriienko V., Lukyanova L., Shepenyuk I., Koinova I., Zagorsky V. and others.

Onopriienko V. notes that environmental education, as a holistic cultural phenomenon, includes the processes of education, upbringing, personal development, should be aimed at the formation of environmental culture as part of the system of national and civic education of all segments of Ukraine's population (including environmental education through public environmental organizations and adult education), ecologization of academic disciplines and training programs, as well as professional environmental training through basic environmental education. According to the author, the subject of environmental education is the problem of environmental education and upbringing, while the subject of cultural ecology - the problem of the influence of nature on culture, in the narrow sense - the preservation of the cultural environment. Ecological education of youth and adults and the ecology of culture are an important part of education because they help to form the continuity and reproducibility of ecological knowledge. [11,12]

L. Lukyanova's scientific works are focused on the problems of ecological education and didactic principles of ecological education of adults. In particular, she notes that the importance of ecological education of adults increases taking into account modern socio-economic factors and raising ecological educational standards. Age features, which must be taken into account in the process of organizing environmental education for adults, are becoming increasingly important. We distinguish three groups of principles (general didactic, environmental education and andragogical and fundamental principles of adult education). [13]

I. Shepenyuk defines environmental education as one of the parts of continuing education. In her research, the author notes that the XXI century is witnessing two types of development, transformation or changes. The first type is a scientific, technological and physical development. The second one includes social, cultural and spiritual changes. The tempo of these two transformations is different, they develop at different speeds. Technological development is almost always ahead of social changes. This discrepancy creates a gap that widens over time. Adult education is one of the most effective tools for teaching people how to best communicate and how to prepare for future challenges. [14]

I. Koinova focuses on the forms of environmental education. The author notes that at the present stage a combination of formal and non-formal environmental education for young people and adults is more effective and efficient. It is expedient to introduce it by carrying out various actions, travels, camps, trainings, the organization of study groups and clubs, research work of youth. These two forms of environmental education must complement each other to form environmental awareness and culture of the population.

The church can offer ecological education for the adult population and a change in our irrational way of life to a nature-oriented one. Pope Benedict XVI in his encyclical "The Price of Truth" states that economic means or education alone will not be enough to preserve nature. These means are important, but the decisive factor is the "holistic moral attitude of society", and therefore a high environmental culture. Priests should 
encourage the public to be responsible for nature, cultivating in them an environmental awareness and personal responsibility for pollution or environmental damage. [15]

The Ukrainian Greek Catholic Church is actively involved in environmental education. For several years in a row, the church has been explaining to the public about the dangers of burning stubble and refusing to use plastic flowers in the cemetery.

It is worth noting the legal provision of environmental adult education of V. Zagorsky. He says that in the third millennium environmental education should become a necessary component of harmonious environmentally sound development. It will be most effective only if it is carried out for the whole duration of a person's life. The creation of such system of environmental education should be legally recognized by constitutional norms as the basis of state environmental policy. [16]

The author also sees the goal of environmental adult education in ensuring the goals of sustainable development. This can be achieved through the awareness of economic, political and environmental interdependence of the modern world, in which the decisions and actions of individual countries can lead to negative environmental global consequences. In this regard, environmental education should help to develop a sense of responsibility and solidarity between countries and regions as a basis for a future international world order that guarantees the preservation of the environment. [16]

\subsection{Bibliometric analysis by scientific fields}

The next step in our study was to identify the fields in which scientific papers with the keyword "environmental education" are published. The most popular field, in which articles with the keyword "environmental education" are published, is social sciences $(35,4 \%)$, followed by environmental science $(28,9 \%)$ and agronomic science $(7,4 \%)$. (see Figure 4 )

We would like to note the development of the IT industry, where more and more scientific papers with the keywords "environmental education" are starting to appear. In 2019 the figure was 1,8\%, while in 2017 it was $0,7 \%$. With the development of technologies, especially in 2020, education moved more to online environment. As a result, there are many online courses, webinars, etc. on environmental education, including the ones for adults. In our opinion, even the concept of "education" has acquired a much broader meaning than before 2020. If, earlier educational activities in most cases were conducted offline in the format of personal communication, the realities of today require the obtaining of knowledge and educational information from the Internet by using modern information technologies.

Ukraine is developing its potential in the IT sphere and in the markets of educational services. Ukraine ranks 35 th in the development of educational technologies. [17]
Although Ukraine does not occupy a leading position, there is a positive trend. Environmental adult education can play a significant role in online education.

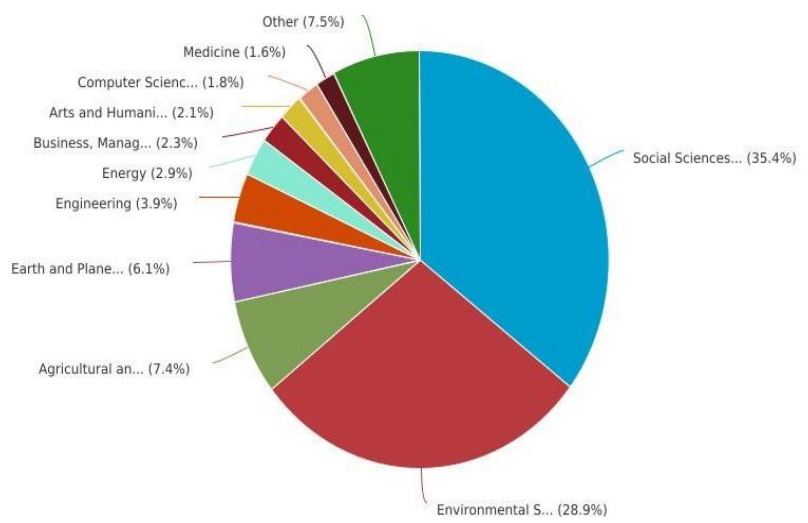

Fig. 4. Papers in the field of "environmental education" classified by field (Scopus Database).

The main purpose of environmental education is the development of environmental competences of citizens. It is known that it is currently one of the reasons for the renewal of education. Competence is the ability to act effectively outside of learning activities. Undoubtedly, environmental competence is one of the key ones in today's world. It is a manifestation of ecological culture in the "zone of responsibility" of an individual.

Environmental education provides particularly relevant and clear opportunities to demonstrate the need for joint solutions to global problems that go beyond national and state boundaries. It is known that environmental pollution does not comply with any borders. As noted by M. Wallström, the former Commissioner for the Environment of the European Commission, polluted waters and contaminated air crossed our borders much earlier than we began to think about opening them for border trade. If we really want to improve the environment, we must start working in the field of environmental education together and at the most serious level. The essential goal of environmental education and enlightenment is to develop the environmental competence of people. It is known that at present it is one of the grounds for updating education. [18]

In the XXI century education should become an individual right and collective responsibility of people. The implementation of the concept of a lifelong education is as important social goal as the introduction of a basic education at the beginning of the 20th century. As a consequence, we will receive a revolution of its kind in educational systems, in the content of training and educational programs, and to a large extent this will be realized thanks to multidisciplinary approaches in the related fields. [19]

The analysis of the past helps to understand the future. In today's culture there are two main directions the separation of society from nature and rapprochement, mutual adaptation or co-adaptation of society and nature. The first of these two trends has a history of its development lasting several millennia. At present it has reached a seemingly marginal manifestation, but still 
continues to unfold, seeking to be realized in the future. The probable future for many generations of people is possible only with the dominance in the very near future of another trend - co-adaptation of society and nature. [20]

When organizing environmental education for adults it is necessary that it strengthens people's awareness and perception of environmental problems as personal problems that directly affect their quality of life; contributes to the realization of the prospects of personal and social development on the basis of the principles of scientifically sound nature management.

Environmental education should be based on the basic postulate that a way out of the environmental crisis in modern conditions is possible. Almost everyone agrees that we have a responsibility to keep our planet inhabited, it is much harder to get people to behave accordingly. The keys to solving the global environmental problem are in the reassessment of worldview values; in changing priorities, as well as in the normalization of the population through family planning, in tireless practical work on the implementation of the main directions in environmental protection. [21]

\section{Conclusions}

Conducting a bibliographic analysis according to the keywords "environmental education" it can be argued that the diversity of views on this thematic cluster is high. At the same time, each author in one way or another mentions the dialogue between man and nature, which is impossible without environmental education of young people and adults. Environmental education of adults is becoming especially relevant and requires qualitative changes, the latest methods and approaches, the use of international experience.

The transition from formal environmental education to "education for sustainable development" should be based on the knowledge about the development of society, economy and natural environment, environmental culture and a sense of personal responsibility for the environment. Environmental education and upbringing are focused on the active interaction of man with nature, built on a scientific basis, on the perception of man as part of the nature.

Ecological knowledge, supplemented by value orientations, is the basis of ecological culture and ecological thinking. They promote the awareness of values, help solve complex environmental problems facing humanity, ensure the comfort of living in the future and contribute to the preservation and enhancement of unique diversity.

Therefore, the development of the system of ecological education of adults and environment upbringing contributes to the formation and development of ecological culture.

\section{References}

1. S. Pryima, Y. Dayong, O. Anishenko, Y. Petrushenko, A. Vorontsova, Lifelong learning progress monitoring as a tool for local development management. Problems and Perspectives in Management. 16(3). 1-13. (2018).

2. T. Pritchard, Environmental education. Biological Conservation, 1(1), 27-31. (1968)

3. H. Lotz-Sisitka, J. Fien, M. Ketlhoilwe. Traditions and new niches: An overview of environmental education curriculum and learning research. International handbook of research on environmental education. 194-205. (2013)

4. A. Gough, N. Gough, The denaturation of environmental education: Exploring the role of ecotechnologies. Australian Journal of Environmental Education, 32(1). 30-41. (2016)

5. H. Kopnina, Education for the future? critical evaluation of education for sustainable development goals. Journal of Environmental Education. 72-79. (2020)

6. P. Bootrach, N. Thiengkamol, T. Thiengkamol, Environmental education strategy. Applied Environmental Education and Communication, 14(4), 200-212. (2015).

7. J. Delia, M. Krasny, Cultivating positive youth development, critical consciousness, and authentic care in urban environmental education. Frontiers in Psychology. 8. (2018).

8. C. J. Fitzwilliams-Heck, Experiences and practices of environmental adult education participants. Environmental Education Research, 25(12), 1804-1805. (2019).

9. P. Walter, A. Earl, Public pedagogies of arts-based environmental learning and education for adults. European Journal for Research on the Education and Learning of Adults, 8(1), 145-163. (2017).

10. K. Alsaadat, The engineering and structure of environmental adult education. International Journal of Civil Engineering and Technology, 9(12). 485-490. Retrieved from www.scopus.com (2018)

11. V. Onopriienko, Ecological education in the system of agricultural personnel training: [monograph]. Kyiv: Knowledge of Ukraine, 307. (2010)

12. V. Onopriienko, Man in the natural environment: the role of environmental education and upbringing. 11 (18). Sumy: SNAU, 15-18. (2009)

13. L. Lukyanova, Didactic principles of ecological education of adults. Pedagogical process: theory and practice, 1 (4). 78-87. (2009)

14. I. Shepenyuk, Ecological education of adults as a link of continuous education Materials of the international scientific-practical conference. Poltava: Astraya. 412-414 (2012)

15. I. Koinova, New approaches to environmental education in Ukraine. Bulletin of KhNU named after Karazina. Ecology. 16. (2017)

16. V. Zagorsky. Environmental education as an important factor in education for sustainable development. Scientific Bulletin, 17. (2008)

17. A. Lysachok, I. Onopriienko, I. Koval, L. Rudenko, $\mathrm{V}$. Chaikovska. Innovative development in IT 
Sphere in the Context of the Industry 4.0 Concept: the Case of Ukraine. International Journal of Advanced Trends in Computer science and Engineering. 9. 188-197. (2020)

18. T. Mukhlaeva. Environmental education for adults as a link in continuing education In the modern world. Vestnik: pedagogy. 1 (12). (2009)

19. O. Slinko, Ecological education as an integral part of personality formation. Proceedings of the International scientific-practical conference "Methods of teaching natural sciences in secondary and higher. 225-226, Poltava, May 29-30 (2014)

20. T. Desyatov, Trends in the development of adult education: European experience. Adult education: theory, experience, prospects. Issue 1 (8) 182-190. (2014)

21. L. Prokhorova, Ecological education and upbringing of youth as a basis of ecological culture of society. Discourse in the conditions of variability of socio-cultural space: materials of the Ukrainian scientific-practical conference with international participation dedicated to the 95th anniversary of Melitopol State Pedagogical University. Melitopol: Bohdan Khmelnytsky Moscow State Pedagogical University Publishing House. 143-146. (2018) 